\title{
CONTEXTUALIZING TAUTOLOGIES: FROM RADICAL PRAGMATICS TO MEANING ELIMINATIVISM
}

\author{
TOMOHIRO SAKAI \\ Atomi University
}

\begin{abstract}
The purpose of this paper is to show that the linguistic meaning of tautological sentences of the form $X$ is $X$ does not correspond to any propositional content and to propose an analysis based on Contextualism, in particular on Meaning Eliminativism, its most extreme form. On the one hand, the radical-pragmatic assumption, shared even by recent cognitive approaches, that $X$ is $X$ expresses a logical tautology leads to various paradoxes. On the other hand, the radical-semantic view that its interpretations cannot be fully calculated by universal principles suffers from theoretical shortcomings. I will argue that the simple fact that $X$ is $X$ consists of two applications of $X$ to the same object provides the basis for the interpretation of $X$ is $X$.*
\end{abstract}

Keywords: tautology, linguistic meaning, Contextualism, Meaning Eliminativism

\section{Introduction}

Sentences of the form $X$ is $X$, illustrated in (1), seem to express a logical tautology such as $\mathrm{X}=\mathrm{X}$ or $\forall \mathrm{x}[\mathrm{X}(\mathrm{x}) \rightarrow \mathrm{X}(\mathrm{x})]$, which, as Wittgenstein (1922: 4.461, 5.142) puts it, is meaningless as such and does not talk about the world.

(1) a. Boys are boys.

b. War is war.

c. Cats are cats if they don't catch mice.

Yet tautologies as given in (1) are commonly used to convey something. The question then arises as to how such tautological sentences can convey non-trivial content. To answer this puzzling question, two types of analyses have been proposed in the literature: the radical pragmatic approach and the radical semantic approach.

* I am indebted to anonymous reviewers of English Linguistics for their helpful comments and suggestions on earlier versions of this paper. This work was supported by Grant-in-Aid for Young Scientists (B) (No. 22720149).

English Linguistics 29: 1 (2012) 38-68 -38-

(C) 2012 by the English Linguistic Society of Japan 
The purpose of this paper is to show that both approaches are seriously flawed and to propose an alternative analysis based on Contextualism, in particular on Meaning Eliminativism, its most extreme form (Recanati (2004)). The organization of the paper is as follows. Section 2 will review the previous studies on tautologies and show that the pragmatic approach is superior to the semantic approach if it is equipped with a cognitive perspective. Section 3 will point out four problems with the pragmatic approach, before showing, on the one hand, that $X$ is $X$ does not express any propositional content at the semantic level and, on the other hand, that the word $X$ should not be associated with any specific meaning. Section 4 will propose a contextualist analysis of $X$ is $X$, focusing on the cases where it expresses a homogenization of $\mathrm{X}$ or an actor-character relation.

2. The Radical Pragmatic Approach and the Radical Semantic Approach

2.1. The Radical Pragmatic Approach

It is Grice (1975/1989) who originally addressed the question of how tautologies are interpreted. According to Grice (1975: 52/1989: 33), such remarks as (2) infringe the maxim of Quantity to the extent that they are totally uninformative at the level of what is said, and they are only informative at the level of what is implicated.

(2) a. War is war.

b. Women are women.

This is all he says about tautology. It is not clear what kind of implicature (2a, b) have, nor how the implicatures are calculated in terms of the maxim of Quantity. Later, entirely in the Gricean spirit, Levinson (1983: 110-111, 124-125) maintained that (2a) literally means (3a) and implicates (3b).

(3) $\quad$ a. $\quad \forall x[\mathrm{~W}(\mathrm{x}) \rightarrow \mathrm{W}(\mathrm{x})]$

b. Terrible things always happen in war, that's its nature and it's no good lamenting that particular disaster.

With regard to the mechanism by which (3b) is derived from (3a), he says that "the details of what is implicated will depend upon the particular context" and admits that "exactly how the appropriate implicatures in these cases are to be predicted remains unclear, although the maxim of Relevance would presumably play a crucial role" (Levinson (1983: 111)).

Lyons (1977) and Yasui (1978) emphasize the role of inferences made by the hearer. According to Lyons (1977: 417), "What the addressee does, upon hearing and understanding a tautologous utterance, is to say to himself, as it were: 'There must be some reason for the speaker to tell me 
what he knows I know to be true. What can this reason be?'." This suggestion, however, is circular insofar as the nature of the inference is not made clear. ${ }^{1}$ It would amount to just saying that ( $3 \mathrm{~b}$ ) is yielded by (3a) by means of some inference whereby (3b) is yielded by (3a), just as the doctor in Molière's comedy tries to explain sleep-inducing properties of opium in terms of its soporific power. Curiously enough, radical pragmatists appear generally to be optimistic in this regard, expecting to discover someday a mechanism whereby (3a) implicates (3b), yet without addressing exactly how. This kind of optimism is still found in recent works such as Hige et al. (2010).

\subsection{The Radical Semantic Approach}

Wierzbicka $(1987,1988)$ attacks the optimism displayed by the radical pragmatic position, by denying the effectiveness of Gricean principles for the computation of implicatures. According to Wierzbicka (1987), English tautologies are set phrases associated with language-specific conventional meanings as in (4).

(4) a. $N_{a b s t r}$ is $N_{a b s t r}$ expresses a sober attitude toward complex human activities.

b. $N_{\text {hum.pl }}$ are $N_{\text {hum.pl }}$ expresses tolerance toward human nature.

c. (art) $N$ is (art) $N$ expresses an obligation.

d. An $N$ is an $N$ expresses appreciation, indifference, or absolute generalization.

Wierzbicka contends that these meanings, largely language-specific, cannot be fully captured by universal pragmatic principles. $^{2}$

From a descriptive point of view, this approach is more powerful than might appear at first glance. Nishikawa (2003), for example, criticizes the radical semantic approach by saying that it fails to account for various interpretations of (2a). This sentence might mean "every war is profitable," if uttered by the president of an arm-manufacturing company, which is clearly not a "sober attitude toward complex human activities" as claimed by Wierzbicka (1987). This objection, however, misses its target. Notice that (4) is not intended to be an exhaustive list. Wierzbicka (1987: 105) explic-

1 Moreover, as Sakai (2009b) points out, inferences as described by Lyons (1977) are in tension with what Recanati (2004) calls the Availability Principle, according to which the process of working out what is implicated by the sentence must be consciously available to the conversational participants. I will not go into this issue here, though.

${ }^{2}$ For a radical semantic analysis of French tautologies, see Schapira (2000, 2005). 
itly mentions that "[1]imitations of space make it impossible for a comprehensive survey to be offered here." To the criticism made by Nishikawa (2003), Wierzbicka would then reply that the interpretation Nishikawa notes is in fact another conventional meaning of (2a). Schapira (2005) even claims that the French tautology of the form une femme est une femme ( $a$ woman is a woman) has two conventional meanings, one of which is appreciation for women and the other contempt. ${ }^{3}$

From a (meta-)theoretical point of view, however, the radical semantic approach has several shortcomings. First, it is in principle non-falsifiable. Under this approach, having interpretation $\mathrm{A}$ is equal to having conventional meaning $\mathrm{A}$, while not having interpretation $\mathrm{B}$ is equal to not having conventional meaning B. There would then be no way to falsify hypotheses proposed in this framework. Second, radical semantic explanations would necessarily be circular. On the one hand, if asked why (2a) can convey (3b), the radical semanticist might answer, "Because ( $3 b)$ is one of the conventional meanings of (2a)." On the other hand, if asked why she thinks (3b) is one of the conventional meanings of (2a), she might answer, "Because (2a) can convey (3b) in certain contexts." This is clearly circular. Third, the radical semantic analysis seems to be at odds with Grice's (1989: 47) Modified Occam's Razor, according to which senses are not to be multiplied beyond necessity. Wierzbicka (1988: 222) attempts to justify her approach by saying, "One starts assuming (Occam's razor) that there is only one meaning, one spells out that hypothetical meaning in an independently established semantic metalanguage, and then one checks if the proposed semantic formula accounts correctly for the entire range of the item's use. If it doesn't account for it, one tries to revise the formula accordingly. If this doesn't help one posits two (or more) different meanings." This explanation, however, ignores the possibility that the first meaning posited goes in the wrong way. It is rather the validity of the very first meaning that should be put under close scrutiny. Fourth, as Ward and Hirschberg (1991: 509) point out, the fact that some aspects of meaning conveyed by tautologies are language-specific does not constitute evidence that the interpretation of tautologies cannot in principle be defined in terms

\footnotetext{
3 The fact that a woman is a woman can convey these two attitudes was first pointed out by Miyake (1972).
} 
of universal pragmatic principles. ${ }^{4}$ The radical semantic approach indeed fails to capture what tautologies in different languages have in common, as shown in the quasi-literal translations of Jean-Luc Godard's movie Une femme est une femme.

(5) a. French (original): Une femme est une femme.

b. English: A woman is a woman.

c. German: Eine Frau ist eine Frau.

d. Spanish: Una mujer es una mujer.

e. Italian: La donna è donna.

d. Japanese: Onna wa onna dearu.

This forces the radical semanticist to partly admit the validity of the Gricean approach, by saying that "I do not wish to deny that the various 'tautological constructions' in different languages have something in common, and that they may be partly explained in terms of some language-independent principles such as Grice's maxim of quantity" (Wierzbicka (1987: 9899)). This is surprising, given that the radical semantic position claims to be an antithesis to the radical pragmatic approach. ${ }^{5}$ It might even be possible to say that the radical semantic approach embodies some kind of defeatism, in that it immediately gives up accounting for the phenomenon in universalistic terms. Finally, Wierzbicka $(1987,1988)$ fails to falsify the radical pragmatic approach even within the range of the phenomena for which she claims that the Gricean approach is bound to fail. Note that Levinson's (1983) approach can be schematized as follows.

(6) a. Premise 1: linguistic meaning of tautology (= logical tautology)

b. Premise 2: pragmatic principles such as Grice's (1975/1989) maxims

c. Premise 3: contextual assumptions

d. Conclusion: implicature of tautology

According to this schema, a tautological sentence yields an implicature in interaction with universal pragmatic principles and contextual assump-

${ }^{4}$ A similar point is made by Taylor (2003: 117) with regard to prepositions: "Yet the non-equivalence of prepositions across languages is no reason for accepting the view that prepositional usage is essentially arbitrary."

${ }^{5}$ Ward and Hirschberg (1991: 509) are misled by Wierzbicka (1987) when they say "Wierzbicka concludes, then, that there are no universal principles by which tautological utterances are interpreted." This is not what Wierzbicka says, as we have seen above. She only denies the omnipotence of the Gricean program. 
tions. In order to argue against this scenario, it must be proved that conclusion (6d) can never be drawn under any contextual assumptions. It should be noted that, even if it happens that, as claimed by Wierzbicka, (6d) cannot be drawn from $(6 a-c)$, all one can know is that at least one of the premises should be abandoned, and there is no algorithm by which one can determine which one(s) should be discarded. ${ }^{6}$ If one chose some appropriate contextual assumptions, it might be possible to draw (6d) from $(6 a, b)$. Insofar as the premises (6a) and (6b) are not proved to be invalid, the radical pragmatic position is not refuted at all. Falsifying schema (6) is thus no easy task, contrary to what might be suggested by Wierzbicka (1987, 1988). ${ }^{7}$

\subsection{A New Gricean Approach}

The problem so far is that no detailed analysis has been proposed within the radical pragmatic framework, which has provoked the attack from the radical semantic position. This difficulty disappears, however, with Ward and Hirschberg (1991). Taking a radical pragmatic perspective, they formulate the interpretation of a tautological utterance as in (7) (Ward and Hirschberg (1991: 511)).

(7) a. $\mathrm{S}$ has affirmed a tautological utterance of the form $a$ is $a$, which appears to add nothing to our mutual beliefs in general, and, in particular, nothing to our mutual beliefs about 'a';

6 This is known as Duhem-Quine thesis in the philosophy of science. This thesis says that it is impossible to test a hypothesis in isolation, since innumerable background assumptions are involved in the hypothesis.

7 Fraser (1988) and Okamoto (1993) propose analyses which lie between the two positions we have seen. Fraser (1988: 217-218) associates English tautologies with the following conventional meaning: "An English nominal tautology signals that the speaker intends that the hearer recognize: (a) that the speaker holds some view toward all objects referenced by the NP; (b) that the speaker believes that the hearer can recognize this particular view; (c) that this view is relevant to the conversation." The view the speaker holds toward all the X's is determined pragmatically. For example, Business is business might convey such propositions as "Business is \{cutthroat/money-making/enjoyable/unenjoyable/time-consuming/unpredictable\}." Okamoto (1993) claims that Japanese tautologies of the form $X w a X d a$ have the core meaning "the category of an item identified as $X$ cannot be changed under any circumstances," which might produce implicatures in context. The problem with Fraser (1988) and Okamoto (1993) is that they do not falsify the radical pragmatic schema in (6), thus failing to show the necessity to postulate the conventional meanings above. 
b. Assuming that $\mathrm{S}$ is observing the Cooperative principle, then, by the maxims of Quantity and Relation, $\mathrm{S}$ has said as much as $\mathrm{s}$ /he truthfully can that is relevant about ' $\mathrm{a}$ ';

c. S might have produced utterances of a similar form, say, 'a is b', which could have added something to our mutual beliefs about ' $a$ ';

d. S chose not to utter such alternatives;

e. thus $\mathrm{S}$ implicates that these alternatives are not relevant for the purposes of the exchange.

For example, (8a) is uttered to reject such alternatives as (8b).

(8) a. Terrorism is terrorism.

b. Terrorism is sometimes justifiable.

This analysis seems to be on the right track, since it can account for the fact that (2a) conveys (3b) in certain contexts. According to (7), (2a) would convey ( $3 b$ ) if uttered to a person who thinks that we can sometimes prevent terrible things from happening in war.

The interpretation formulated in (7), however, does not do the job it is supposed to do. Consider again (8). If the speaker of (8a) implicates that (8b) is not relevant for the purpose of the exchange, as claimed by Ward and Hirschberg (1991), then (8a) would convey (9).

(9) Terrorism is never justifiable.

But it is clear that (9) fulfills the condition stated by (7c), that is, (9) is an utterance of the form ' $a$ is b' which could have added something to our mutual beliefs about 'a.' Then (7) predicts (8a) rejects both (8b) and (9), leading to a contradiction. Although Ward and Hirschberg (1991) do not seem to be conscious of this problem, some mechanism is called for to prevent (8) from rejecting (9). All we have to do to this end would be to revise (7c) as (10c).

(10) c. S might have agreed with utterances of a similar form, say, ' $a$ is b', which could have been uttered by someone other than $\mathrm{S}$, and which could have added something to our mutual beliefs about ' $a$ ';

With this revision, the utterance which ' $a$ is a' rejects must be one that could have been uttered by someone other than S. A typical context where a tautological sentence is uttered would then be something like (11).

(11) A: Some X's are not P.

B: X's are X's. (implicature: All X's are P)

In (11), A utters a sentence of the form ' $a$ is $b$,' which is rejected by a sentence of the form ' $\mathrm{a}$ is a' uttered by $\mathrm{B}$, in conformity with (10c). In fact, 
this is exactly the schema proposed by Fujita $(1988,1990,1992)$. In the next section, we will review her pioneering works on tautology. ${ }^{8}$

\subsection{The Cognitive Approach}

Although Fujita $(1988,1990,1992)$ has arrived at the schema in (11) independently of radical pragmatics or radical semantics, the analysis she proposes rests heavily on the radical pragmatic assumption that a tautological sentence, meaningless by itself, gets its meaning in use. What is new with Fujita $(1988,1990,1992)$ is that in her system the very fact that tautologies lack meaning delivers implicatures without evoking Gricean principles. Recall that the question the radical pragmatic approach has tried to answer is how meaningless sentences can convey meaningful content. Fujita (1998, $1990,1992)$ does away with this question by taking the view that tautologies are only uttered in contexts in which a self-evident proposition can contribute as such to the purpose of conversation in one way or another.

On this picture, it is typically when two views are opposed to each other that such sentences are uttered. This might be illustrated with the dialogue in (12) which we have seen in Section 2.3.

(12) A: Terrorism is sometimes justifiable.

B: Terrorism is terrorism.

(12A) divides acts of terrorism into two groups as shown in (13).

(13) a. justifiable acts of terrorism

b. unjustifiable acts of terrorism

(12B) rejects the differentiation in (13), by reminding A that all acts of terrorism are the same. Here the tautological sentence serves as a reminder of a self-evident truth. It draws A's attention to a property shared by all acts of terrorism through reminding $\mathrm{A}$ of the fact that all acts of terrorism are acts of terrorism. This leads to the homogenization as opposed to the differentiation of the two groups in (13); there is no relevant distinction to be made between (13a) and (13b). According to Fujita (1990: 122, 1992: 101-102), a tautological utterance of the form $X$ is $X$ can provide the strongest argument in favor of the homogenization of the members of the category X, by virtue of expressing a genuine logical tautology, which by definition is necessarily true.

The function of tautological sentences of the form $X$ is $X$ could then be

${ }^{8}$ Although Fujita $(1988,1990,1992)$ exclusively deals with French tautologies, her analysis seems to be valid cross-linguistically. 
schematized as in (14).

(14) a. In the preceding context, the members of the category $\mathrm{X}$ are, explicitly or not, differentiated into two groups.

b. $X$ is $X$, by virtue of expressing a genuine logical tautology, reminds the addressee of a property shared by all the occurrences of $\mathrm{X}$.

c. The homogenization based on a genuine logical tautology forces the addressee to reject the division made in (14a).

This schema has had a great influence on later works on tautological sentences especially in Japan. One might even call this homogenization-based analysis "the standard theory of tautologies" for several reasons.

First, it is now generally agreed that tautologies can be used to homogenize members of a category, rejecting a differentiation proposed by others (Ward and Hirschberg (1991), Sakahara (1992, 2002, 2008), Okamoto (1993), Cadiot and Nemo (1997), Bulhof and Gimbel (2001), Cadiot and Visetti (2001: 202-203) among others).

Second, Fujita's proposal that a tautological sentence, meaningless by itself, acquires meaning as an objection to a category reorganization proposed by the addressee is reformulated by Sakahara $(1992,2002,2008)$ in terms of cognitive semantics. Discussing the tautological utterance in (15B), Sakahara (2008: 214) says, "[I]t is a genuine logical tautology linguistically as well as logically. The reason why a logically genuine logical tautology is still meaningful is that it is taken as the negation of $(15 \mathrm{~A})$, partition in the form of $[(16)]$."

(15) A: Cats that don't catch mice are not cats.

B: Cats are cats.

(16) $\mathrm{X}$ that is not $\mathrm{P}$ is not $\mathrm{X}$ (e.g. Cats that don't catch mice are not cats.)

It should be noted that Sakahara's homogenization-based analysis of tautologies, now widely known, builds on the proposal first made by Fujita (1988, 1990, 1992).

Third, Fujita's hypothesis according to which a tautological utterance focuses on some property shared by all the occurrences of $\mathrm{X}$ is followed by several authors, whether or not they explicitly cite Fujita's works (Higuchi (1988), Moriyama (1989), Mizuta (1995), Miki (1996), Cadiot and Nemo (1997), Koizumi (1997), Seto (1997), Cadiot and Visetti (2001), Sakahara (2002), and Nishikawa (2003)). Seto (1997: 64-71), for example, claims that the function of tautological utterances is to emphasize the conventional meaning of the word $X$. In (12), what is emphasized by the tautology is 
the conventional meaning of terrorism, which would include the property "unjustified." Similarly, Nishikawa (2003) maintains, within the relevance theoretic framework, that tautological sentences serve as a reminder of an obvious truth about $\mathrm{X} .{ }^{10}$ These characterizations of tautological sentences would be essentially the same as Fujita's original analysis indicated in (14).

As will be shown in Section 3, however, analyses along the lines of (14) lead to several puzzles that, as far as I know, no one has ever pointed out.

\section{Deconstructing the Linguistic Meaning of Tautological Sentences}

\subsection{Illusion of Self-evidence}

As we have seen in 2.4, Fujita $(1990,1992)$ claims that a tautological utterance of the form $X$ is $X$ can provide the strongest argument in favor of homogenizing members of the category $\mathrm{X}$, and that the strong argumentative force exhibited by $X$ is $X$ is due to its logical necessity. This is assumed, expressly or tacitly, by many other authors such as Higuchi (1988), Moriyama (1989), Seto (1997), Nakamura (2000), and Sakahara (2002, 2008). This assumption can be shown, however, to be fallacious to the extent that it is based upon a confusion between "tautological" on the one hand and "self-evident" or "obvious" on the other.

A self-evident or obvious truth can indeed provide a strong argument for some conclusion. For instance, it is self-evident or obvious that every animal will die. Suppose that we are discussing whether Fido, our best friend, is an animal or a robot. You say that he is an animal and will die, whereas I insist that he is a robot and will never die. If Fido turns out to be an animal, however, I will surely accept the conclusion that he will die, given that this conclusion is based upon the obvious fact that every animal

9 According to Seto (1997), this is made possible by the fact that tautologies express the identity "A = A." If the meaning of $A$ includes the property "unjustified," then the utterance $A$ is $A$ will convey, Seto claims, the proposition that all the A's are unjustifiable. This line of argument will be criticized in section 3.1.

10 Under Nishikawa's (2003) analysis, the interpretation of the predicate $X$ involves an ad hoc concept of X (cf. Carston (2002: 357-359)), which, she claims, always represents an obvious truth about X. For example, an ad hoc concept of war might be "something cruel that make many victims." Nishikawa, however, does not explain why the predicate $X$ is so interpreted. Insofar as the mechanism by which tautological sentences express such an obvious proposition is not made clear, Nishikawa's analysis would fall on the side of radical semantics, despite her commitment to Relevance Theory. A similar drawback can be found in Koizumi (1997). 
will die. This is illustrated in Table 1.

Table 1

\begin{tabular}{|c|c|c|c|}
\hline & $\mathrm{A}(\mathrm{f})$ & $\mathrm{D}(\mathrm{f})$ & $\forall \mathrm{x}(\mathrm{A}(\mathrm{x}) \rightarrow \mathrm{D}(\mathrm{x}))$ \\
\hline $\mathrm{A}=$ my belief 2 & 1 & 1 & 1 \\
\hline $\mathrm{B}$ & 1 & 0 & 0 \\
\hline $\mathrm{C}$ & 0 & 1 & 1 \\
\hline $\mathrm{D}=$ my belief 1 & 0 & 0 & 1 \\
\hline
\end{tabular}

$\mathrm{A}(\mathrm{x}): \mathrm{x}$ is an animal $\mathrm{D}(\mathrm{x})$ : $\mathrm{x}$ will die f: Fido 1: true 0 : false

My first belief corresponds to line D. Now that Fido turns out to be an animal, I must abandon this belief and adopt A or B, where "Fido is an animal" (A(f)) is true. Line B is excluded, because it is not compatible with the obvious truth that every animal will die $(\forall \mathrm{x}(\mathrm{A}(\mathrm{x}) \rightarrow \mathrm{D}(\mathrm{x})))$. So, I must accept A, where Fido is an animal and will die. What should be noted here is that the proposition that every animal will die excludes the belief, given in B, that Fido is an animal but will not die. If I accept this proposition as true, I cannot continue to hold the belief that Fido will not die. This constitutes the argumentative force of the proposition "every animal will die."

In contrast, as discussed by Todayama (2000: 48-49, 2002: 38-40), a tautological proposition cannot be used to justify any belief, since it is always true by definition, independently of whatever belief one holds. To illustrate the point, we give here an example which is different from Todayama's. Suppose that we are discussing whether certain acts of terrorism are justifiable or not. We agree that an act of terrorism, $a$, is unjustifiable, while we disagree whether or not another act of terrorism, $b$, is unjustifiable. For you, it is unjustifiable, whereas for me, it is justifiable to some extent. Your belief thus corresponds to line A and mine to line B in Table 2 below.

Table 2

\begin{tabular}{|c|c|c|c|}
\hline & $\mathrm{U}(\mathrm{a})$ & $\mathrm{U}(\mathrm{b})$ & $\forall \mathrm{x}(\mathrm{T}(\mathrm{x}) \rightarrow \mathrm{T}(\mathrm{x}))$ \\
\hline $\mathrm{A}=$ your belief & 1 & 1 & 1 \\
\hline $\mathrm{B}=$ my belief & 1 & 0 & 1 \\
\hline $\mathrm{C}$ & 0 & 1 & 1 \\
\hline $\mathrm{D}$ & 0 & 0 & 1 \\
\hline
\end{tabular}

$\mathrm{U}(\mathrm{x}): \mathrm{x}$ is unjustifiable $\mathrm{T}(\mathrm{x}): \mathrm{x}$ is an act of terrorism

1: true

0 : false 
Now suppose that in this context you utter sentence (17a), which, according to the pragmatic approach, expresses proposition (17b).

(17) a. Terrorism is terrorism.

b. All acts of terrorism are acts of terrorism. $(\forall \mathrm{x}(\mathrm{T}(\mathrm{x}) \rightarrow \mathrm{T}(\mathrm{x})))$ Under the scenario depicted by Fujita (1988, 1990, 1992), Sakahara (1992, 2002, 2008) and Seto (1997), sentence (17a) could, with its strongest argumentative force, convince me that act $b$ is also unjustifiable. But this would never happen. The proposition in (17b), as shown in Table 2, is true independent of whatever belief I hold. It does not then exclude any belief. So, while believing (17b), I can perfectly continue to believe that act $b$ is justifiable. This clearly shows that it is only an illusion to imagine that a tautological proposition that is supposed to be expressed by $X$ is $X$ provides the strongest argument in favor of the alleged implicature of the sentence. On the contrary, it provides nothing.

Why then do so many researchers commit such a fallacy? The answer is likely to lie in the fact that they mix up "what is said" and "what is implicated" in the sense of Grice (1989). Note that, in Grice's (1989) framework, (17a) says (17b) and implicates (18).

(18) All acts of terrorism are unjustifiable.

(17b) is a tautological proposition, whereas (18) is a self-evident or obvious proposition, which could be used to homogenize members of the category "terrorism." Here the argumentative force of (18) is often wrongly taken for that of (17b). This is a fatal confusion, given that the question to answer is how (17a), which literally expresses (17b), can convey (18). The claim that the obvious proposition (17b) expressed by (17a) reminds us of the obvious truth in (18) is based on a fallacy of begging the question, to the extent that it presupposes the argumentative force of (18), from which that of $(17 \mathrm{a})$ originates, not vice versa.

The above argument shows, against the scenario described in (14), that logical tautologies such as $\forall \mathrm{x}[\mathrm{X}(\mathrm{x}) \rightarrow \mathrm{X}(\mathrm{x})]$ or $\mathrm{X}=\mathrm{X}$ can play no role in deriving the implicatures of an utterance. There is no doubt that $X$ is $X$ has homogenization effects, but it is no less evident that the effects do not come from its tautological character.

\subsection{Paradox of Logical Tautology}

The argument in the preceding section has shown that the assumption that $X$ is $X$ literally expresses a genuine logical tautology is useless in deriving any implicature of the utterance. This assumption, however, is not only useless, but even harmful, as pointed out by Sakai (2009a). Consider (19). 
(19) a. Ugly or not, a cat is a cat.

b. Ugly or not, a cat is a cat if only it catches mice.

(Sakahara (1992: 65), translated from French) If (19a) expresses (20a), as assumed by the pragmatic approach, then (19b) will express (20b).

(20) a. (19a): $\forall \mathrm{x}[\mathrm{C}(\mathrm{x}) \rightarrow \mathrm{C}(\mathrm{x})]$

b. (19b): $\forall \mathrm{x}[\mathrm{C}(\mathrm{x}) \wedge$ catch_mice $(\mathrm{x}) \rightarrow \mathrm{C}(\mathrm{x})]$

As indicated in (20b), the conditional if only it catches mice brings the restriction " $\wedge$ catch_mice(x)" to the formula. Under the pragmatic assumption that (19a) literally expresses (20a), this restriction gives rise to a paradox.

Let us begin with the sentence in (21), discussed by Fauconnier (1997: 138-140).

(21) Bears are intelligent when they have blue eyes.

Notice first that (21) is a weaker assertion than (22).

(22) Bears are intelligent.

In general, proposition $\mathrm{P}_{1}$ is weaker than another proposition $\mathrm{P}_{2}$ if and only if accepting $\mathrm{P}_{2}$ implies accepting $\mathrm{P}_{1}$ but not vice versa. (21) is weaker than (22) because those who accept (22) must necessarily accept (21), but not vice versa. The propositions expressed by (22) and (21) can be represented as in (23a) and (23b) respectively.

(23) a. (22): $\forall \mathrm{x}[\mathrm{B}(\mathrm{x}) \rightarrow \mathrm{I}(\mathrm{x})]$

b. (21): $\forall \mathrm{x}[\mathrm{B}(\mathrm{x}) \wedge$ have_blue_eyes(x) $\rightarrow \mathrm{I}(\mathrm{x})]$

As Fauconnier (1997: 139) points out, the effect of the when clause in (21) is to partition the set of bears, ascribing the predication in the main clause only to a subset of bears. This is the reason why the assertion made by (21) is weaker than that made by (22).

Now compare (20) with (23). If the restriction " $\wedge$ have_blue_eyes(x)" in (23b) weakens the assertion made by (23a), then the restriction " $\wedge$ catch mice(x)" in (20b) should also weaken the assertion made by (20a). But this possibility is totally excluded, because (20a) is by definition the weakest proposition, i.e., you can never deny the truth of (20a) under any circumstances. To put it simply, in (20b), the restriction " $\wedge$ catch_mice(x)" is expected to weaken proposition (20a), but (20a) can never be weakened. Accordingly, the pragmatic approach fails to account for the co-occurrence of (19a) and a restrictive clause as in (19b). To avoid this problem, the pragmatic assumption that (19a) literally expresses (20a) must be abandoned.

One might object to this argument by saying that the conditional in (19b) does not weaken the assertion, for some reason or another. But this objection is ad hoc, insofar as it is not justified on any independent ground. It 
also suffers from empirical shortcomings. For one thing, the conditional in (19b) does weaken the assertion, since, as Sakahara (1992, 2002, 2008) notes, what (19b) homogenizes is not the category of "cats," but that of "cats that catch mice." Cats that do not catch mice are not taken into account here. For another, as Sakahara $(1992,2002,2008)$ also notes, there are some tautological sentences whose assertions are clearly restricted by conditionals. For instance, (24a) is equivalent to (24b) (Sakahara (2008)).

(24) a. Cats are cats only if they catch mice.

b. Cats that don't catch mice are not cats.

The assertion made by (24a) is by no means the same as that made by Cats are cats. The effect of the conditional in (24a) is to exclude the cats that don't catch mice from the predication in the main clause. If, as the pragmatic approach suggests, cats are cats expressed a logical tautology, this exclusion would not make sense. Since logical tautologies are necessarily true, it is not possible in principle to restrict their validity. It should now be concluded that the analysis given in (14) is fallacious.

One might still insist, in order to keep the assumption that the linguistic meaning of $X$ is $X$ corresponds to a logical tautology, that the predicates in (19b) or (24a) are not interpreted literally. For example, they might denote only "prototypical cats," or some properties of cats, following the suggestions made by Mizuta (1995), Koizumi (1997), Sakahara $(2002,2008)$ and Nishikawa (2003). ${ }^{11} \quad$ These alleged solutions, however, are not only ad hoc, but also fail to deal with the problems to be discussed in the next two sections.

\subsection{Paradox of Identity Statement}

(25) can have an interpretation in which Hitchcock plays the role of Hitchcock himself (Fujita (1988: 26, translated from French), cf. Fauconnier (1985: 18, 144)).

(25) In that movie, Hitchcock is Hitchcock.

It is evident that this interpretation has nothing to do with the prototype of Hitchcock or his properties. It might perhaps be represented as "In that movie, Hitchcock is the character named Hitchcock," where "the character named Hitchcock" is an ad hoc concept of Hitchcock (cf. Nishikawa

11 The suggestions made by these authors are independent of the assumption that the literal meaning of $X$ is $X$ always corresponds to a logical tautology. They merely intend to describe its intuitive interpretations. 
(2003)). A question which arises here is this: What is the literal meaning expressed by (25)? Is it the tautological proposition that Hitchcock is identical to himself? If so, the literal proposition expressed by (26a) would be the proposition that Hitchcock is not identical to himself, and that expressed by (26b) would be the proposition that Hitchcock is identical to Churchill.

(26) a. In that movie, Hitchcock is not Hitchcock.

b. In that movie, Hitchcock is Churchill.

This amounts to saying that (26a) and (26b) are necessarily false, as far as their literal meanings are concerned. But this is absurd.

One might be tempted to say that (25) is another use of $X$ is $X$, where no logical tautology is expressed. If so, it would be mistaken to try to reduce the meaning literally expressed by (25) to a logical tautology. Under this view, $X$ is $X$ would have two uses: tautological use and non-tautological use. In the former case, a tautological sentence expresses a homogenization, whereas in the latter it expresses an actor-character relation. This alleged solution, however, invalidates the very assumption that a logical tautology literally expressed by $X$ is $X$ serves as input to the computation of what is implicated, and hence definitely falsify the schema in (6), upon which the pragmatic analyses are crucially based, including the cognitive analyses proposed by Fujita $(1988,1990,1992)$ and Sakahara $(1992,2002$, 2008).

It should also be noted here that, once the schema in (6) is abandoned, homogenizations and actor-character relations expressed by $X$ is $X$ have practically nothing in common anymore. This suggests that $X$ is $X$ itself does not express any specific proposition. ${ }^{12}$ This leads us to Contextualism, as discussed in 4.1 below.

\subsection{Paradox of Contradictory Utterances}

In this section, it will be shown that the word $X$ in the contradictory sentence $X$ is not $X$ does not have any specific meaning. Consider (27).

(27) Cats are not cats if they don't catch mice. (Sakahara (2008: 213)) Let $\mathrm{P}$ stand for the meaning of the word cat. If "to catch mice" is included in P, then the conditional clause in (27) is contradictory. This

12 This should not be confused with the assumption held by Sakahara (2008: 207) that "a tautological sentence does not have a specific meaning." On the one hand, Sakahara does not prove this. On the other hand, as argued in 3.1, he fails to account for the process whereby the nonspecific meaning of a tautological sentence is turned into a fullfledged interpretation. 
makes the sentence necessarily true, since in general if $A$, (then) $B$ is true if $A$ is false. This is absurd. If "not to catch mice" is included in $\mathrm{P}$, then the conditional clause in (27) is necessarily true. This makes the sentence equivalent to Cats are not cats, since in general the truth value of if $A$, (then) $B$ is equivalent to that of $B$ when $A$ is true. This is also absurd. Therefore, neither property is included in P. Now, in general, if an element $x$ satisfies $\mathrm{P}$, then $x$ continues to satisfy $\mathrm{P}$ even after any property $\mathrm{Q}$ is added to it, provided that $\mathrm{Q}$ is not in contradiction with $\mathrm{P}$. For instance, if water is liquid, then cold water is also liquid. Recall that, as proved above, "not to catch mice" is not in contradiction with P. Hence, a cat should be expected to remain a cat even after it is assigned this property. Sentence (27) contradicts this. There would now be no choice but to deny that the word cat has any specific meaning P. Note that this argument would not be affected by appealing to such notions as "fuzzy category," "abstract schema," or "knowledge-rich meaning," all of which could instantiate $\mathrm{P}$ as used in the proof.

Assuming that $X$ is not $X$ and $X$ is $X$ should be treated in a unified manner, for the analysis of neither should one posit any context-independent linguistic meaning of $X$. This leads us to Meaning Eliminativism, as discussed in 4.1 below.

\section{Constructing the Meaning of Tautological Sentences}

\subsection{Contextualism/Meaning Eliminativism}

Our arguments in 3.1-3.3 suggest, in conformity with those provided by Sakai (2009b), that a tautological sentence of the form $X$ is $X$ cannot be associated with any propositional content. This provides strong support for Contextualism as put forward by Recanati (2004), according to which there is no level of meaning that is both propositional and minimal. The proposition is said to be minimal if it is calculated exclusively on the basis of the conventional meanings of the words constituting the sentence, along with "saturation," a process consisting in the assignment of the values to the variables delivered by grammar. According to Contextualism, minimal propositions, if any, play no role in the interpretation of utterances. This position sharply contrasts with Literalism, as exemplified by the radical pragmatic approach, which advocates the notion of minimal proposition.

The most extreme form of Contextualism is called Meaning Eliminativism, which "denies that words (qua linguistic types) have 'meanings' in anything like the traditional sense - not even abstract or knowledge-rich mean- 
ings" (Recanati (2004: 141)). As such, Meaning Eliminativism provides an ideal case for Modified Occam's Razor touched upon in 2.2. The argument in 3.4 suggests that tautological and contradictory sentences should be analyzed in light of this perspective. Meaning Eliminativism has its origin in the later Wittgenstein. Although Recanati (2004) does not explicitly cite the works by Wittgenstein, my account below draws on Wittgenstein (1953, 1958) and Ambrose, ed. (2001), as well as on Recanati (2004).

As pointed out by Wittgenstein (1953: §80), our language does not fully specify the conditions of application for words. For example, suppose you find a strange chair-like object which suddenly disappears from sight, and appears again some seconds later. It is a chair? Or suppose you have a cat. If the "cat" turns out to speak Latin, is it still a cat? There is no "correct" answer to these questions, because the definitions of chair or cat are not specific enough to enable us to determine whether the objects in question can be so called.

One might think that it would suffice to enrich the definitions. In principle, this may be so. But in practice, this is not feasible, as emphasized by Waismann (1951: 122-123): “As, in fact, we can never eliminate the possibility of some unforeseen factor emerging, we can never be quite sure that we have included in our definition everything that should be included, and thus the process of defining and refining an idea will go on without ever reaching a final stage." This is reminiscent of Wittgenstein's famous rule-following paradox (Wittgenstein (1953: §201, 1958: 141-143), Kripke (1982), Ambrose, ed. (2001: 133)), according to which no course of action could be determined by a rule.

A solution might be suggested by making use of the notion of similarity. If the object in question is sufficiently similar to the other objects we call or called $\{$ 'chair'/'cat'\}, then it is a \{chair/cat\}. The notion of similarity, however, does not help us determine whether it really is a \{chair/ cat\}. The object in question can be similar to the other \{chairs/cats\} in certain respects, but not in others. Then "we have no contextual clues as to which dimensions of similarity matters" (Recanati (2004: 144)). Crucially, "the dimension of similarity is not given, but contextually determined" (Recanati (2004: 145), emphasis in the original). ${ }^{13}$ This is what Wittgenstein suggests in the following passage: "Suppose I gave you a sam-

${ }^{13}$ As Yamaguchi (2005) emphasizes, this is what the arbitrariness of the sign in the Saussurian sense is all about. 
ple, saying 'This is green', and asked you to bring me something green. If you brought me something yellow and I said it did not agree with my idea of green, am I describing a fact of nature? No. To say that something yellow disagrees with the green sample is to give a rule about agreement. That yellow disagrees with green does not follow from anything in the nature of green or yellow. I could instead say that what disagrees with green is something that looks nasty with green, and yellow might be said to agree with green. If something is said to agree or disagree with an idea or thought, we do not find it agreeing or disagreeing. What are called agreement and disagreement is something laid down as a rule" (Ambrose, ed. (2001: 84), emphases in the original). It follows that "[e]ach new application we make is a leap in the dark" (Kripke (1982: 55)). The meaning of a word, as Recanati (2004: 150) puts it, "is not, as in Fregean semantics, a set of conditions of application determined once and for all." It is only after we apply a word blindly that we can talk about the conditions of its application.

Then, under Meaning Eliminativism, does our use of language fall into anarchism? No. The legitimacy of the application of a word depends on whether the members of the community agree with it (Kripke (1982: 96, 99), Recanati (2004), cf. Wittgenstein (1953: §241, 242)). A word P is associated with "source objects," that is, a collection of objects such that the members of the community agree that $\mathrm{P}$ is applied to those objects (cf. Recanati (2004: 148)). ${ }^{14}$ If someone applies the word P to a new object, or a "target object," then it implies that she has judged, often unconsciously, the target object to be similar enough to the source objects of P in relevant ways. Within this framework, "cat" and "table," for example, are said to have different meanings to the extent that they are associated with very different source objects. The judgment, however, is open to disagreement on the part of others. As we will see below, this is the key to understanding contradictory and tautological sentences.

Meaning Eliminativism also sheds light on the notion of linguistic community. Speakers of Japanese call cats "neko," whereas speakers of English call them "cats." Why? Because they speak different languages? Our answer is no. There is in fact no reason for the difference. Both speakers apply the word blindly. That's all. In general, if two or more people ap-

14 Recanati (2004) talks about situations of application of $\mathrm{P}$ rather than objects to which $\mathrm{P}$ is applied. Here we focus on objects for the sake of simplicity. 
ply the same word to the same objects, then they are said to speak the same language. If not, they are said to speak different languages. A language is thus defined by agreements in judgments, not vice versa (cf. Wittgenstein (1953: §241, 242)). ${ }^{15}$ On this picture, English and Japanese are said to be different languages to the extent that their speakers apply words very differently.

\subsection{Minimal Facts about Tautological and Contradictory Sentences}

Under Meaning Eliminativism, which denies that words or sentences have specific meanings independent of their use, the semantic description of $X$ is (not) $X$ must start from the minimal facts about these sentences, as indicated in (28).

(28) a. $X$ is $X$ : The word $\mathrm{X}$ is applied to what the word $\mathrm{X}$ is applied to.

b. $X$ is not $X$ : The word $\mathrm{X}$ is not applied to what the word $\mathrm{X}$ is applied to.

A tautological sentence is characterized by two applications of $\mathrm{X}$ to the same object, say, $a$. Suppose that the first application takes place at $\mathrm{t} 1$, while the second application takes place at $\mathrm{t} 2$. This implies that both $a$ at t1 and $a$ at $\mathrm{t} 2$ are judged to be similar enough to the source objects of X, that is, the other objects to which $\mathrm{X}$ is applied. Conversely, the contradictory sentence of the form $X$ is not $X$ implies that $a$ at t 2 is judged to be dissimilar from the source objects of $X$. As will be discussed in what follows, (28) gives rise to different interpretations depending on who makes the second application of $\mathrm{X}$ and/or under which circumstances $\mathrm{X}$ is applied.

\subsection{Homogenization}

Let us begin by the example in (29).

(29) All soldiers know one must not kill children. For Israel claims to be a state upholding universal values. So how does one kill children without killing children? How does one take life "when one must" without bloodying oneself? Without crossing accepted borders? Very simple. For example, in open-fire regulations (that soldiers are no longer handed out in hardcopy, but

15 A similar point is made by Kripke (1982: 92): "We say of someone else that he follows a certain rule when his responses agree with our own and deny it when they do not." 
only instructed orally), an individual over twelve years of age is not a child.

$A$ child is not a child.

(Palestine monitor, 23 April 2008, italics mine)

The contradictory sentence in (29) says that the Israeli army does not apply the word child to certain individuals to whom other people apply the word. The individuals in question are Palestinians, as suggested by sentence (30), found in the same article.

(30) [A] Palestinian child is not a child according to the instructions they have received.

(Palestine monitor, 23 April 2008) (30) reflects the fact that the Israeli army judges Palestinian children to be dissimilar from other children, namely, individuals found in the collection of the source objects of child. This would correspond to the differentiation of $\mathrm{X}$ as indicated in (14a) above. In this situation, tautological sentences as in (31) can be used to argue against (29) or (30).

(31) a. A child is a child everywhere, just as you say. The man who denies this is more than wrong, he's evil.

(http://www.unfogged.com/archives/comments_2306.html)

b. A child is a child regardless of race.

(http://mybrownbaby.com/2011/08/transracial-families-whywhite-people-adopt-black-children/)

Both sentences in (31) reflect the speaker's attitude that the word child should be applied to every individual to whom the word is once applied, including Palestinians. When uttering (31), the speaker judges Palestinian children to be so similar to other children that they equally deserve to be so called. This is, I argue, the source of the homogenization effect displayed by tautological sentences. The application of the same word $\mathrm{X}$ to $a$ and $b$ reflects the speaker's judgment that $a$ and $b$ are similar enough in relevant ways, while the denial of the application reflects the judgment that $a$ and $b$ do not deserve the same name. Note that, in this account, the effect is not produced by any inference whereby a necessarily true proposition reminds us of an obvious truth about $\mathrm{X}$, nor by any mysterious mechanism whereby the mere focus on the category name $\mathrm{X}$, or the mere repetition of the word $\mathrm{X}$, makes us completely blind to internal differences of $\mathrm{X}$, as assumed by Fujita (1988, 1990, 1992), Sakahara (1992, 2002, 2008), Seto (1997) etc.

4.4. Tautologies as a Reminder of Obvious Truths

The analysis proposed here correctly predicts that $X$ is $X$ can serve as a reminder of an obvious truth about $\mathrm{X}$ or a common property of $\mathrm{X}$ 
(Rey-Debove (1978), Wierzbicka (1987: 109), Higuchi (1988), Moriyama (1989), Mizuta (1995), Miki (1996), Koizumi (1997), Seto (1997), Nishikawa (2003)). As argued above, sentence (31b), for example, reflects the speaker's judgment that the individuals in question are similar enough to other children, i.e. individuals found in the collection of the source objects of child, in relevant respects. If the hearer agrees that the children found in the collection of the source objects are generally blameless, and that this property is relevant for the purpose of the conversation, then (31b) implies that all children, including Palestinians, are blameless. (31b) thus reminds us of an obvious truth about children. The proposition in (32b) conveyed by (32a), as discussed in 3.1 above, can be accounted for in a similar manner.

(32) a. Terrorism is terrorism.

b. All acts of terrorism are unjustifiable.

It should be noted, however, that this by no means defines the function of $X$ is $X$. As is often the case, the individuals found in the collection of the source objects cannot be characterized by one or several common properties, given that categories are often structured according to what Wittgenstein calls "family resemblances" (Wittgenstein (1953: §67)) or "family likeness" (Wittgenstein (1958: 17)). In addition, it is in principle possible for us to be indifferent to internal differences of the category $\mathrm{X}$ without evoking any common properties. Consider (33).

(33) "A child is a child regardless of where a child comes from. Regardless of his color, nationality, ethnicity, every child deserves the best medical care," he [a charity's executive director] said. (ABC News, December 12, 2007) In (33), the director does not have in mind any common properties of children. Rather, he expresses his decision not to change his attitudes toward children under any circumstances, by saying that he will apply the word child to any individuals who have been so called, no matter what properties they turn out to exhibit. The utterance in (33) reflects the speaker's judgment that children he will encounter in new situations are similar enough to other children, yet without evoking any specific properties.

\subsection{Immutability of Categorization}

The present analysis properly captures the immutability of categorization conveyed by $X$ is $X$ (Sakahara (1992, 2002, 2008), Okamoto (1993), Nakamura (2000)). Recall that both utterances in (31) entail that the word child is equally applied to Palestinians. It follows that, uttered to argue against (29) and (30), (31a, b) bring them back to the category of child. 
Note that this account does not rest on the notion of "proposition literally expressed by $X$ is $X$." Sakahara (2002) insists that a tautological sentence, meaningless by itself, can get its meaning by being used to refuse a category reorganization proposed by a contradictory sentence like (29) and (30). According to his claim, the implicature of category immutability would be ascribed to the logical necessity of $X$ is $X$. As argued in 3.1, however, it is a fallacy to think that a genuine logical tautology can produce any effect on the interpretation of a sentence.

\subsection{Restrictive Homogenization}

Let us now return to the problem discussed in 3.2, where (19b), repeated here as (34), has been evoked to discredit the assumption that the linguistic meaning of $X$ is $X$ corresponds to a logical tautology.

(34) Ugly or not, a cat is a cat if only it catches mice.

My explanation is simple enough. By adding the restrictive expression if it catches mice, the speaker of (34) leaves open the possibility that she does not apply the word cat to those that do not catch mice. There is no puzzle here. Similarly, in (35), the restrictive phrase until she is 16 or 18 and of an age to give consent suggests that the speaker might cease to apply the word child when the person in question turns16 or 18 .

(35) But I would say to these men that a child is a child, in her uniform and out of that uniform, until she is 16 or 18 and of an age to give consent.

(http://www.montserratreporter.org/news0702-1.htm)

\subsection{Illusion of Definition}

Consider again (35) above. One might perhaps think that (35) is a mere repetition of the definition of child as given in dictionaries, or even stored in our mental lexicon, because a person who is more than 18 years of age is no longer a child. But this is largely an illusion. As noted in 4.1, the speaker can in principle freely decide whether to apply a word to the object(s) in question. The application of a word is not controlled by the prior identification of its linguistic meaning; hence the compatibility of (35) and (36).

(36) A child is a child, even though the parent might be 90, and the child 60 .

(Szasz (1988: xiii))

Dimensions of similarity upon which the speaker decides to apply the word child are different for (35) and (36). Given that, as emphasized in 4.1, dimensions of similarity are contextually determined, (35) and (36) are not in 
contradiction with each other.

This is also true of encyclopedic definitions of words. Consider (37).

(37) Ichiro is Ichiro, though his average is .281 at this time, 70 points below last year's 351 .

(The Entertainer, June 2008)

The fact that the property of "being a player with a high average," presumably his best known property, is lost does not prevent the speaker from judging, following his own interest, the present occurrence of Ichiro to be similar enough to his past occurrences. This supports the view held by Wittgenstein (1953: §79): "Has the name 'Moses' got a fixed and unequivocal use for me in all possible cases?-Is it not the case that I have, so to speak, a whole series of props in readiness, and am ready to lean on one if another should be taken from me, and vice versa?" The view advocated here is equally consistent with Noya's (2011: 418-419) claim that, as against what the standard semantics assumes, the bearer of a proper name is not an object, but interest in the object. Seen from this perspective, what makes possible the second application of the name Ichiro in (37) is the speaker's invariant interest in the individual in question, which is confirmed by the fact that, ceasing to display the same interest in the individual, the speaker can say, at least in principle, "For me, Ichiro is no longer Ichiro." By this utterance, he claims that the name "Ichiro" should no longer be applied to the person who has been so called. What supports the application of a name is not its reference, but the speaker's interest in the object.

What I have said does not mean, however, that words or names can be used without any limitations. Recall that, on the picture defended here, the legitimacy of the application of a word depends entirely on how the other members of the community evaluate it. What is crucial here is that the evaluation is made at the very moment the word is used. Although the condition of application for a word is not fully determined prior to its use, the application of a word is subject to an evaluation, once it is used in context. The use of a word may provoke contradicting evaluations, as in (38).

(38) Many Churches believe that abortion is wrong, and others believe that abortion is not wrong. The differences being that the membership of the Churches believe, as I do, that a child is a child even if it is in the womb. The other churches feel that a child is only a child after birth.

(http://www.mektek.net/forums/topic/34928-subjective-moralitythe-dangerous-lie/)

Our understanding of child is not specific enough to definitely determine whether or not it is applicable in the situation described in (38). If the dis- 
agreement between members of the community turns out to go beyond the limits, then they are no longer considered to belong to the same community, as suggested in 4.1. This leads us to the investigation of the topic-closing quality exhibited by $X$ is $X$.

\subsection{Topic-closing Quality of Tautological Utterances}

The present analysis also gives a partial account of the topic-closing quality of tautologies as observed by Levinson (1983). Consider (15), repeated here as (39).

(39) A: Cats are not cats if they do not catch mice.

B: Cats are cats.

What is crucial here is that this disagreement is not yielded by the fact that $\mathrm{A}$ and $\mathrm{B}$ do not fully recognize the target object. They know perfectly well what they are talking about. As argued in 4.1, our language does not fully specify the conditions of application for a word. One can in principle freely decide whether or not to apply the word to a new target object. (39A) claims that the word "cat" should no longer be applied to what has been called a cat, if it turns out not to catch mice. ${ }^{16}$ (39B) rejects this claim and decides to continue to apply the word. Recall that, as emphasized in 4.2, a language is defined by agreements in judgments, not vice versa. Under this view, one could say that A and B in (39) do not speak exactly the same language. Although they do speak what is called English, their languages are slightly different by definition. They are using two different words which are both pronounced [kæt]. In the language spoken by A, the animal in question is not a "cat" while in that spoken by B it is a "cat." Here we have two different linguistic conventions. ${ }^{17}$ It would then be impossible for

\footnotetext{
16 Similarly, by saying that "[a] doubt that doubted everything would not be a doubt," Wittgenstein (1969: §450) rejects the way skeptics have used the word "doubt."

17 An anonymous reviewer has pointed out that it is possible to say "From a biological point of view, a cat that does not catch mice is a cat, while from a functional point of view, it isn't." In this utterance, does the speaker participate simultaneously in two different linguistic conventions? Our answer is no. Here he just proposes a complex definition of "cat." For him, the proper application of "cat" depends on the point of view being taken. Just as "Your mother is an animal" is only justified when uttered, say, in a biology class, the appropriateness of "A cat that does not catch mice is a cat" is sensitive to the situation of utterance. If you do not agree to this complex definition of "cat," then your language is slightly different from his. Note, however, that this does not preclude the possibility for one and the same person to participate in two different linguistic conventions, i.e., to be bilingual.
} 
one of them to refute the other by using his or her own language, just as, in cases like (30) and (31), Palestinians would never succeed in refuting the instructions the Israeli soldiers have received. ${ }^{18}$ They share no language by which they talk about the "cat," since the word denotes different things for them. As they are outsiders to each other, their conversation stops there. This constitutes, I argue, the topic-closing quality displayed by $X$ is $X .^{19}$

This might also be closely related to the problem raised by Taylor (2003: 59) in connection with divergences of prototypes: "Presumably, in day-today exchanges, differences in conceptual centre are likely to pass unnoticed, especially if the lexical items in question can be applied to an identical range of referents. It is an open question, however, to what extent such differences in the conceptual centre might sometimes hinder communication, or even lead to gross misunderstandings." As indicated above, tautological utterances make us notice the divergence of the range of objects to which the word $X$ can be applied, thus hindering the communication between the applier and the non-applier of $X$.

\subsection{Actor-character Relation}

Finally, I briefly present my proposal for the analysis of tautological sentences which express actor-character relation as in (40a).

(40) a. In that movie, Hitchcock is Hitchcock.

b. In that movie, Hitchcock is not Hitchcock.

c. In that movie, Hitchcock is Churchill.

As we have seen in 3.3, the sentences in (40) pose a puzzling problem for the pragmatic approach. In the analysis proposed here, however, they can be treated as special cases of (28). What makes (40) different from other examples is that the (non-)applier of the word is the director of the

18 Of course Palestinians could "persuade" the Israeli army to abandon the instructions. This might be in close connection with what Wittgenstein (1969) suggests through the following comments: (i) "We should be trying to give him our picture of the world. This would happen through a kind of persuasion." (Wittgenstein (1969: §262), emphasis in the original) (ii) "At the end of reasons comes persuasion. (Think what happens when missionaries convert natives.)" ( $\$ 612$, emphasis in the original).

19 This proposal can be seen as an elaboration of Nakamura's (2000) insight, which attributes the topic-closing quality of tautologies to the fact these sentences are used to reject some categorizing principle underlying the claims made by the addressee. 
movie. ${ }^{20}$ In movie-making, the director has the privilege to decide on the cast and other people have no choice but to follow her decisions. If the director says Mary is Cleopatra, then she is. Hence, (40b) says that the director does not apply the word Hitchcock to the person to whom people apply the word in normal situations. (40c) says that the director applies the word Churchill to the person to whom people apply the word Hitchcock in normal situations. Finally, (40a) says that the director applies the word Hitchcock to the person to whom people apply the same word in normal situations. As is clearly seen, there is nothing puzzling here.

\section{Conclusion}

After rejecting the widely held view that the linguistic meaning of tautological sentences of the form $X$ is $X$ corresponds to a logical tautology as suggested by (6) or (14), we have offered an alternative analysis based on Contextualism as opposed to Literalism. What $X$ is $X$ has in common throughout its uses is not a proposition that it is supposed to literally express, but the fact that the word $X$ is applied twice.

Previous studies on tautologies have assumed, expressly or tacitly, that the reason why they are so commonly used lies in the fact that they serve as a reminder of some previously established facts, such as conventional meaning of $\mathrm{X}$, conventional categorization of $\mathrm{X}$ or common properties of $\mathrm{X}$. The assumption that $X$ is $X$ expresses a specific proposition or that the word $X$ expresses a specific concept, however, cannot account for the various facts discussed in Section 4. Rather, it is precisely because the concept X can never be fully defined that tautological sentences exist in our language. If the concept $\mathrm{X}$ were ever stable across individuals, what would be the point of uttering $X$ is $X$, or more strikingly, $X$ is not $X$ ? These sentences do not express any proposition about an existent concept $X$; they reflect the ongoing and everlasting process of defining the very concept $X .^{21}$ If so, the analysis of these sentences must start from their use, not from the alleged context-independent meaning of the sentences or of the words therein. We

20 Of course, (40) can be uttered by someone who watches the movie. Even in this case, however, the initial (non-)applier of the word must be the director.

21 Although we will not go into the details here, the following remark made by Bulhof and Gimbel (2001: 290) might be incorporated into the framework advocated here: "Deep tautologies say nothing about the world, but they speak loudly about the nature of the concepts that are being used to describe the world." 
could call this "contextualist turn." This revives Wittgenstein's "meaning as use." The context-independent linguistic meaning of $X$ is $X$ is thus entirely eliminated from semantics.

An objection to the elimination of context-independent linguistic meaning is made by Jackendoff (2002: 280): "There is a germ of insight here [i.e. in the view held by Wittgenstein (1953)], in that the message conveyed by an expression is indeed heavily influenced by one's understanding of the context [...]. But on the other hand, the expression must convey something with which the context can interact. If it did not, a hearer could in principle know from the context what message was intended, without the speaker saying anything at all!" Jackendoff is admittedly right in saying that the linguistic expression must play a role in conveying a message, but what I want to claim here is that it is a prejudice to think that what the linguistic expression contributes must be some context-independent linguistic meaning. Recall that the application of an expression $\mathrm{E}$ to a target object reflects the speaker's judgment that it is similar enough to the source objects of $\mathrm{E}$, to which $\mathrm{E}$ would legitimately be applied by the members of the community. As Recanati (2004: 152) points out, the application of the word red and that of the word rectangle would reflect different judgments made by the speaker. Thus, even if these words lack "context-independent meaning" as traditionally construed, they do contribute something different in relevant ways.

One might object here that the fact that the source objects of red and rectangle are different must be accounted for by the difference of their context-independent linguistic meanings. According to this objection, the difference of meaning yields that of use, not vice-versa. There is no a priori reason, however, to believe that the meaning of words must be established prior to their use, especially given that words have never been dissociated from their contexts of use since they came into existence. This prejudice results from what Wittgenstein $(1958: 17,18)$ calls "craving for generality" or "the contemptuous attitude towards the particular case." As emphasized by Wittgenstein (1953: §219), we usually apply words blindly. "We need have no reason to follow the rule as we do" (Wittgenstein (1958: 143), italics in the original). The use of words need not always be controlled by the conditions of application previously established. In fact, it must not. As shown in 3.4, if it were, it would not even be possible to account for the very existence of tautological or contradictory sentences. Their existence proves, in my opinion, that our language is what might be called "Meaning Eliminative language." Faced with this "contextualist turn," linguists 
must now take seriously the question: What is the point of positing a context-independent meaning for a sentence or even a word? Contrary to the commonly held belief, what must be proved is not the nonexistence of context-independent meaning, but its existence. Once the notion of contextindependent meaning is abandoned, the traditional distinction between 'what is said' and 'what is implicated' also should come under close scrutiny. We have shown that, insofar as $X$ is $X$ is concerned, this distinction has no role to play, since what is said by $X$ is $X$ has been totally eliminated from the computation of its interpretation.

\section{REFERENCES}

Ambrose, Alice, ed. (2001) Wittgenstein's Lectures: Cambridge, 1932-1935, Prometheus Books, Amherst, New York.

Bulhof, Johannes and Steven Gimbel (2001) "Deep Tautologies," Pragmatics \& Cognition 9-2, 279-291.

Cadiot, Pierre and François Nemo (1997) "Analytique des Doubles Caractérisations," Sémiotiques 13, 123-143.

Cadiot, Pierre and Yves-Marie Visetti (2001) Pour une Théorie des Formes Sémantiques: Motifs, Profils, Thèmes, PUF, Paris.

Carston, Robyn (2002) Thoughts and Utterances: The Pragmatics of Explicit Communication, Blackwell, Oxford.

Fauconnier, Gilles (1985) Mental Spaces: Aspects of Meaning Construction in Natural Language, MIT Press, Cambridge, MA.

Fauconnier, Gilles (1997) Mappings in Thought and Language, Cambridge University Press, Cambridge.

Fraser, Bruce (1988) "Motor Oil Is Motor Oil: An Account of English Nominal Tautologies," Journal of Pragmatics 12, 215-220.

Fujita, Tomoko (1988) "Une Femme Est une Femme: X ÊTRE X Koubun Kaishaku no Kokoromi (Une Femme Est une Femme: A Proposal for the Interpretation of the X ETTRE X Construction)," Furansugogakukenkyu 22, 15-34.

Fujita, Tomoko (1990) "X ÊTRE X Koubun Saikou (The X ÊTRE X Construction Revisited)," Kandagaigodaigakukiyou 2, 115-133.

Fujita, Tomoko (1992) "X ÊTRE X Koubun, Daisankou: Purototaipuriron to Sooshoobun (A Third Investigation on the X ETTRE X Construction: Prototype Theory and Generic Sentences)," Kandagaigodaigakukiyou 5, 91-109.

Grice, Paul (1975) "Logic and Conversation," Speech Acts, Syntax and Semantics 3, ed. by Peter Cole and Jerry L. Morgan, 41-58, Academic Press, New York. [Reprinted in Studies in the Way of Words, Paul Grice, 1989, 22-40, Harvard University Press, Cambridge, MA.]

Hige, Ikuhiko, Koichiro Kawashima and Junya Watanabe (2010) Furansugogaku 
Gairon (Introduction to French Linguistics), Surugadai, Tokyo.

Higuchi, Mariko (1988) "Tootorojii no Imirikai (Understanding Tautology)," Kwassuironbunshu 31, 167-186, Kwassui Women's College.

Jackendoff, Ray (2002) Foundations of Language, Oxford University Press, Oxford.

Koizumi Tamotsu (1997) Jooku to Retorikku no Goyouron (Pragmatics of Jokes and Rhetoric), Taishukan, Tokyo.

Kripke, Saul, A (1982) Wittgenstein on Rules and Private Language, Harvard University Press, Cambridge, MA.

Levinson, Stephen (1983) Pragmatics, Cambridge University Press, Cambridge.

Lyons, John (1977) Semantics, Vol. 2, Cambridge University Press, Cambridge.

Miki, Etsuzo (1996) "Evocation and Tautologies," Journal of Pragmatics 25, 635648.

Miyake, Ko (1972) Eigogaku to Gengogaku (English Linguistics and Linguistics), Sanseido, Tokyo.

Mizuta, Yoko (1995) "Tootorojii ga Imi wo Motsu toki (When Tautologies Have Meaning)," Gengo 24.13, 52-55.

Moriyama Takuro (1989) "Jidoo Hyogen wo megutte (On Self-Identical Expressions)," Machikaneyama ronso 23, 1-13, Osaka University.

Nakamura, Yoshihisa (2000) “'Kachi wa Kachi' 'Make wa Make': Tootorojii ni Hisomu Ninchitekihitei ('Victory Is Victory' 'Loss Is Loss': Cognitive Negations Hidden in Tautologies)," Gengo 29.11, 71-76.

Nishikawa, Mayumi (2003) "Tautology no Kousatsu: Ad hoc Gainen no Shiten kara (A Study on Tautology: From the Perspective of Ad hoc Concept)," Goyouronkenkyu 5, 45-58.

Noya, Shigeki (2011) Katarienumono wo Kataru (Speaking the unspeakable), Kodansha, Tokyo.

Okamoto, Shigeko (1993) "Nominal Repetitive Constructions in Japanese: The 'Tautology' Controversy Revisited," Journal of Pragmatics 20, 433-466.

Recanati, François (2004) Literal Meaning, Cambridge University Press, Cambridge.

Rey-Debove, Josette (1978) "Le Sens de la Tautologie," Le Français Moderne 46-4, 318-332.

Sakahara, Shigeru (1992) “Tootorojii ni tsuite (On Tautologies)," Gaikokugokakenkyukiyou 40-2, 57-83, University of Tokyo.

Sakahara, Shigeru (2002) "Tootorojii to Kategoriika no Dainamizumu (Tautologies and Dynamism of Categorization)," Ninchigengogaku 2: Kategoriika (Cognitive Linguistics 2: Categorization), ed. by Toshio Ohori, 105-134, University of Tokyo Press, Tokyo.

Sakahara, Shigeru (2008) "Dynamism of Category Reorganization in Tautology," Language Across Cultures (NCKU FLLD Monograph Series Vol. 1), 205-221.

Sakai, Tomohiro (2009a) "Zenshoomeidai to Tootorojii (Universal Propositions and Tautologies)," Proceedings of the 9th Annual Meeting of the Japanese Cognitive Linguistics Association, 225-235.

Sakai, Tomohiro (2009b) "Le Débat entre Littéralisme et Contextualisme: Le Cas des Énoncés Tautologiques du Type X ÊTRE X," Bulletin d'Études de Linguistique 
Française 43, 1-18.

Schapira, Charlotte (2000) "La Phrase Tautologique," Lingvisticae Investigationes 23, 269-286.

Schapira, Charlotte (2005) "Existe-t-il une Polysémie Propositionnelle?" La Polysémie, ed. by Olivier Soutet, 345-362, Presses de l'Université de Paris Sorbonne, Paris.

Seto, Ken-ichi (1997) Ninshiki no Retorikku (Rhetoric of Recognition), Kaimeisha, Tokyo.

Taylor, John R. (2003) Linguistic Categorization, 3rd ed., Oxford University Press, Oxford.

Todayama, Kazuhisa (2000) Ronrigaku wo Tsukuru (Constructing Logic), University of Nagoya Press, Nagoya.

Todayama, Kazuhisa (2002) Chishiki no Tetsugaku (Philosophy of Knowledge), Sangyoutosho, Tokyo.

Waismann, Friedrich (1951) "Verifiability," Logic and Language, ed. by Anthony Flew, 117-144, Blackwell, Oxford.

Ward, Gregory L. and Julia Hirschberg (1991) "A Pragmatic Analysis of Tautological Utterances," Journal of Pragmatics 15, 507-520.

Wierzbicka, Anna (1987) "Boys Will Be Boys: 'Radical Semantics' vs 'Radical Pragmatics'," Language 63, 95-114.

Wierzbicka, Anna (1988) "Boys Will Be Boys: A Rejoinder to Bruce Fraser," Journal of Pragmatics 12, 221-224.

Wittgenstein, Ludwig (1922) Tractatus Logico-Philosophicus, Routledge and Kegan Paul, London.

Wittgenstein, Ludwig (1953) Philosophische Untersuchungen/Philosophical Investigations, tr. by G.E.M. Anscombe, Basil Blackwell, Oxford.

Wittgenstein, Ludwig (1958) Blue and Brown Books, Basil Blackwell, Oxford.

Wittgenstein, Ludwig (1969) Über Gewissheit, Basil Blackwell, Oxford, On Certainty, ed. by G.E.M. Anscombe and G.H. von Wright, tr. by Denis Paul and G.E.M. Anscombe, Harper Torchbooks, New York.

Yamaguchi, Hiroyuki (2005) Ningenkagaku no Tetsugaku (The Philosophy of Human Science), Keisoushobou, Tokyo.

Yasui, Minoru (1978) Gengai no Imi (Connotative Meaning), Kenkyusha, Tokyo.

\section{Source of Example}

Szasz, Thomas Stephen (1988) The Myth of Psychotherapy: Mental Healing as Religion, Rhetoric, and Repression, Syracuse University Press, Syracuse.

[received September 20 2011, revised and accepted February 5 2012] 
Department of Humanities

Atomi University

1-9-6, Nakano, Niiza-shi

Saitama 352-8501

e-mail: madara@tky.3web.ne.jp 